INVIESTICATION ON INCOMIRRESSIMLE TUIRIBULENT BOUNDARY LAYER WITH MAXIMUM DECELERATION

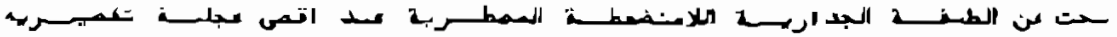

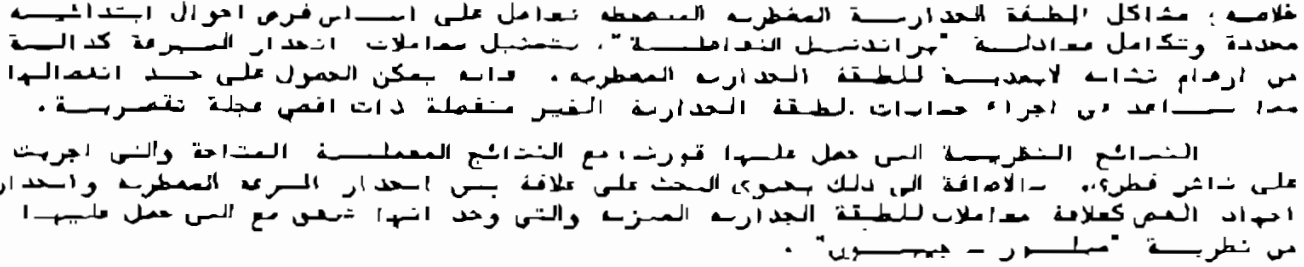

ADSTRACT- Incompressible tu:bulent boundary laver problems are rolved based on certan assumed boundary condilions, by integrating Prandil integral equation. Representing the velocity profile parameter as a function of dimensionless similarity number of curbulent boundary layers, a separirion critera can be achieved. Thus helps in solving the attached boundary layers with max mum jeceleration. data obrained Jor radial dilluser.

Moreover, this investigation contains relation berween the eurbulent velocity profile ard shear stress profile in a parametric form lor equiliberum boundary layer and agree well with thar obtaned Irom Mellor-Gibson theory.

\title{
NOMENCLATURE
}

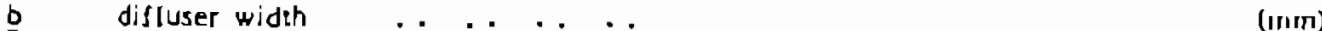

b elfective widet $\ldots \ldots \ldots$

c velocily at the outer edge of boundary layer

$c_{\text {I }}$ local skin friction roefficient, $\tau_{w} /\left(1 / 2 . \rho L^{-2}\right.$

$(\mathrm{mm})$

$\tau_{\tau}$ snear siress telocity, $\sqrt{\tau_{w} / \rho}$.

$(\mathrm{m} / \mathrm{s})$

$c_{\infty}$ tree strealri velociry.

$(\mathrm{m} / \mathrm{s})$

$c_{x}$ velocity of the flund inside the boundary layer in $x-d i r e c i 10 n(m / s)$

$(\mathrm{m} / \mathrm{s})$

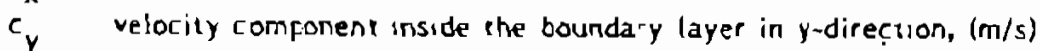

$(\mathrm{m} / \mathrm{s})$

$H$, convential shape factor, $6 * 1$

$(\mathrm{m} / \mathrm{s})$

I defect-shape lactor

P presture,

$\left(N / m^{2}\right.$

Re ${ }^{*}$ momentum inickness Reyrolds number, $\bar{c}, \delta * / \nu$ 
$x$ coordinate in the direction of the wall, (m)

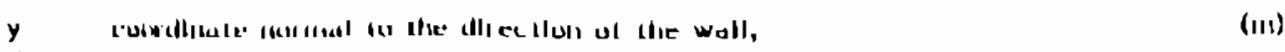

$\delta$ boundary layer thickness,

8. boundary layer displacement thickness. $\int_{0}^{\infty}\left(1-c_{x} / \bar{c}\right) d y, \quad$ (m)

8.* boundary layer momentum thickness, $\int_{0}^{\infty} c_{x} / \vec{c}\left(i-c_{x} / \vec{c}\right) d y, \quad$ (m)

$\Lambda$ Euler number, $1 / \bar{c} . d \bar{c} / d x \cdot \delta \cdot$

$Y$ kinematic viscosity of lluid, $\quad\left(\mathrm{m}^{2} / \mathrm{s}\right)$

$\rho$ densiry ol lluid, $\quad\left(\mathrm{kq} / \mathrm{m}^{3}\right)$

$\tau$ shear stress, $\quad\left(\mathrm{N} / \mathrm{m}^{2}\right)$

$\tau_{w} \quad$ wall shear stress, $\quad\left(\mathrm{N} / \mathrm{m}^{2}\right)$

\section{I- INTRODUCTION}

The prediction ol boundary layer development under various llow conditions playes an important role in the design of a wide variety of fluid machinery components. For exarnple, boundary layers in the presence of unlavourable pressure gradient play a signilicant role in the case of radial dilfusers. This causes the viscous boundary layers to break away from the walls and greatly alfecis the diffuser perlormance.

There have been several siudies applied to the problem of predicting dilluser elfic:ency and design parameters. In particular, Ackerel and Albring [1,2], Leibe und Jahn [3], and Rucht, [4] and Sörgel [5] have all presented experimental work to deal with this phenomenon, In [6] an investigation about turbulent boundary layer by dillerent roughnesses was given exper(me!tally.

This paper 15 concerned with developing of a mathematical model to obtain a criteria for maximum deceleration in cadial dilfusers. This is based on the integration of the momentum integral equation under certain assumed boundary condirions. Assuming that the velocily prolile parameter has an oprimum value, $\Lambda_{\text {of }}$ of a magnieude about 0.00094 , and the form parameter, $\mathrm{H}_{1,2}$ ranges between 1.4 and 1.6 lor maximum deceleration.

\section{2- COVERNING EQUATIONS}

The governing equation of mean flow for incompressible turbulent llow is the momentum integral equation [7] given as:

$$
\frac{d \delta \cdot *}{d x}+\left(2+\frac{\delta *}{\gamma_{*}^{*}}\right) \frac{\delta \cdots}{\bar{c}} \frac{d \bar{c}}{d x}=\frac{\tau_{w}}{\rho \bar{c}}=\frac{c_{1}}{2}
$$

Equation (I) is normalized by using ,

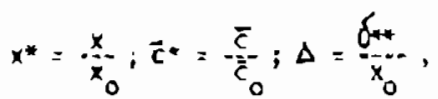

$x_{\text {and }} \bar{c}$ being appropriate reference quantilies. Thus, $x_{\text {will }}$ be the length from the center of the radial dilfuser to the beginning of the paraflel walls : $\bar{c}$ the component of velocity at the inlet by $x a t$ the edge of boundary layer. Fig. (1) illustrates the coordinate system used for the radialdilluser. 
Equation ( 1 ) becomes :

$$
\frac{d \Delta}{d x^{*}}+\left(2+H_{12}\right) \frac{\Delta}{\bar{c}^{*}} \frac{\partial \vec{c}^{*}}{d \bar{x}^{*}}=\frac{r}{2}
$$

The oprimum value of Euler number, $\Lambda_{\mathrm{ODt}}=-\frac{\Delta}{\overline{\mathrm{c}}^{*}} \frac{d \bar{C}^{*}}{d \mathrm{x}^{*}}$, was found to be close to 0.00094

[0] and so one adopts this constant value of, $\Lambda$, for the andysis presented here. Moreover, by this value of, $\Lambda$, the local skin Iriction coefficient, $c_{f}$ is very small and diminishes, and the Iorm parameter, $H_{12}=\delta_{*} / \delta^{* *}$, has a magnitude of 1.4 to 1.6 [5], so that equation (2) can be interrated with $c_{1}, 0$ and $\Lambda_{0 p t}$ and $11_{12}$ are constants. Equation (2) therefore yrelds

$$
\frac{d \Delta}{d x^{2}}+\left(2+H_{12}\right)\left(-\Lambda_{\partial p r}\right)=0
$$

Separating the variatiles and integraving, this equation (3) one gets:

$$
\Delta=\left(2+H_{12}\right) \Lambda_{\text {upt }} \cdot x^{*} \cdot c \text {, }
$$

where $c=\Delta_{D}$, since $\delta_{*} \delta_{*}=$ const and $c_{i} \rightarrow 0$ when the lirst tern on the right liand side of equation 14$\}$ is equal to zero. Then the solution of Eq. (4) is given as

$$
\delta_{* *}^{* *}=\left(2+\frac{\delta_{*}^{*}}{\delta_{0}^{*}}\right)\left(\Lambda_{0 p:}\right) \frac{x}{x_{0}}+\frac{\delta_{0} \cdot .}{x_{0}}
$$

Recalling the incegral definition of ecuation (1), and substitubing for $c_{1}=0$, this yields

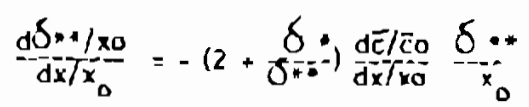

Rearranging equation (6) by separating the variables and integldung one gets,

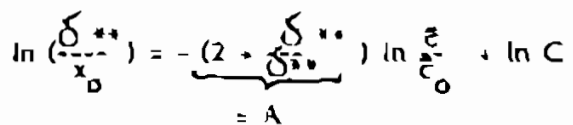

or

$$
\left.\ln \left(\frac{\delta}{x_{0}}\right)=-c \ln \frac{(\bar{C}}{\bar{C}_{0}}\right)^{A} \text {, }
$$

where $c=\frac{\delta_{0} \cdots}{x_{0}}$. since $\bar{c}-\bar{c}_{0}$ al $x=x_{0}$

Therefore $\frac{\delta * *}{x_{0}}=\left(\frac{\bar{c}}{\varepsilon_{0}}\right)^{-A} \cdot\left(-\frac{\delta_{0}}{x_{0}}\right)$

Equation (5) and (8) are two independent expressions for $5 * / x_{0}$. Combining thrre two equations (5), (B) and are Rees a simple equation,

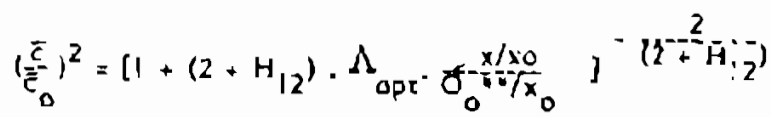


using a mean value for $H_{12}=1.9$ and $\Lambda=0.00094$ and substituting in equation (9), the tallowing lorm for the velockly diatributiun, Ofs the recuvery luctur, is

$$
\left(\frac{\vec{c}}{c_{0}}\right)^{2}=\left[1+0.0033-5 \frac{x / x_{0}}{j_{0}-\frac{1}{2} / x_{0}} 1^{-0.5714}\right.
$$

Equation $(10)$ is used in the analysis to ob:ain the effect of the initial velocity on the diffuser performance.

In addition, an equilibrium Iurbulent boundary layer is one for which the gross properties of the outer region, constituting some $85-938$ (8) of the total boundary layer, can be scaled with a single parameter such as the boundary-layer delect thickness, $\theta$, where

$$
\theta=\int_{0}^{\infty} \frac{\bar{c}-c x}{c_{\tau}} d y \text {. }
$$

${ }^{c} \tau$, the friction velocily, expressed in terms of the local wall shear strcss, $c_{1,}$ by ${ }^{q} \bar{t}^{-}=$

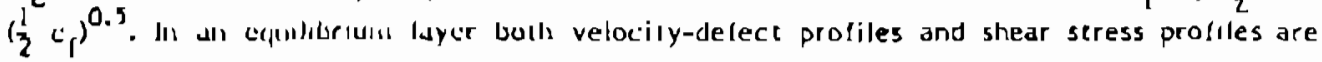
sell similar. This sell-similarily of relocity-delect prolides, deinonstrated by Clauser [9], that forzan equilibrium boundary layer $\left(\bar{c}-c_{\tau}\right) / c_{\tau}$ is iunction of $y / \delta$ only. Hence. $\left(\bar{c}-c^{2}\right)^{2} / c^{2}$, is a simblar unique lunction and thus in such a boundary layer the deleci shape lactor, I, delined as :

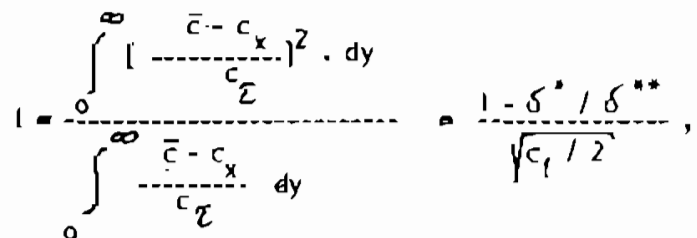

will be a constant. Through algebric manbulation the convential shape 1 actor, $H_{1 / 2}=\delta^{*} / \delta^{* *}$, can be expressed in terins of the delect shape lactor, l, by:

$$
H_{1,2}=\left[1-\left(c_{1} / 2\right)^{0.5} \cdot 1\right]^{-1}
$$

which is constant in an equilibrium turbulent boundary layer as long as the local skin friction, $c_{f}$ is invarianl $[10$, II]. This aprees with the previous assumed boundary condition for integrating the momentum intepral equation.

For characterising the shear stress layers the proper value is the dimensionless shear siress tangent at the wall $[12]$,

$$
\frac{\partial\left(\tau / \tau_{w}\right)}{\partial\left(y / \delta^{\mu}\right)_{y=0}}=\frac{\partial P}{\partial x} \frac{\delta}{\tau_{w}}=-\frac{1}{\bar{c}} \frac{d \bar{c}}{\partial x} \frac{\delta^{*}}{c_{1} T^{-}}
$$

Developing the shear stress distribution across the flow in Mac-Laurin series, so it comes as first and important torm. This magnitude will be evalualed in the same time through the pressure gradient at the outer edge of the boundary layer.

The relationship between velocigy delect-proble and shear stress profile, i.e., betiveen both parameter, Eq. (1I . b) and Eg. (12) is evaluaced Irom experiments (13). For equilibrium 
boundary layers it Iollows from Mellor-Gibson theory [14]. Fig. 4, illustrates this relationship between velocity defect prolile and the dimensionless shear stress tangent at the wall. The expr.mental data originated from boundary layers which hos steady derrieration till separation exlitibis.

\section{PRESENTATION AND DISCUSSIONS OF RESLLTS}

The two equation lormerly obzajned;

$$
-\delta_{0}=\frac{\sigma_{0}}{x_{0}}+\frac{0.0033-\frac{x_{0}}{x_{0}}}{x_{0}}
$$

and

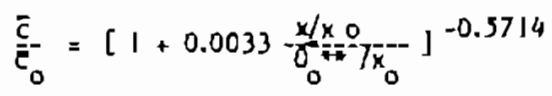

are evaluated and plotted in ligures 2 and 3. Equation (5) emphathises that the momentum thickness increases lincary. In figure (2) indicates the lincar increase in momentum llsickness which obtained Irom equation (S).

Equation (10) for the velocity distribution shows that the velocity at the boundary layer edge decreases according to a gower function. This relation given by equallon (10) is illustrated in ligure (3). Mloreover, figure (3) shows the marked ellect of the initial ralue of momentum thickness (sulfix o), while smaller thickness of boundary layer results in higher values of decelerabur wall these correspemding to rhisker values of boundary layer thickness.

Figure 4 describes the relat on between the velocity prolile and shear-stress profile. For comparison the curve for equilibrium boundary layer is drawn,wlikdi ind cales a uncquivoc.al join both parameter. The deviation berween both curves is due to simplification in the calculation. In addition, boundary layers with essential another :ype of boundary condirions have remarkable deviation from the drawn curve.

Fig. (s) shows the relatian between $\Lambda$ values and momentum rhickness Reynolds number, Re $\mathrm{g}^{-*}$. This illustration agrees and in harmony with use physical perception, afterwhich in near srejralou essericialy pressierc and inertia lorees are only cllective.

For satislying the boundary cundition for llows near separation a constant $\Lambda$ values is selected, e.g. J.00049 that gua-znice the ar:aclied flow.

\section{4- CONCLUSIONS}

The conclusions of the present investigation may be listed as follows :

i) Formulas have been obtained [equations ( 5 ) and eq. (10) ] which represent adcquately the theoretical cata for the influence ol the boundary layer growth in momentuin thickness at diffuser inlex on its perfurmance. Increasing the velocity at diffuser inlet increases the momentum thickness and cecreases :he recovery factor remarkably. So, to obtain maximum deceleration the initial value of momentum thickness must be decreased.

ii) $A_{n}$ independent, also indirert, check has been made on the grocedure of velocity prorile matching to determine the local shear stress. It shows a reasonable agrcement with that given by Mellor-Gibson theory (Fig. 5) [14].

iii) Near separation pount the pressure erid inerua forces ar: only elfectuve. 
M. 74 S. F. Hanna

\section{REFERENCES}

[I] Ackeret, J

"Grenzschichten in geraden und gekrümmten Dılfusoren. Grenzschichrforsclionf (Derlin, Göringen, Heidelberg 1967)

[2] Abbring, w. et. al. Entwicklung eines radiallüfter mit hohem wirkungsgrad-Maschinenbaurechnik, H.8.

(3] Liepe und Jahn

"Einlluss des Dralles auJ ruhende und rotierende Radialdillusoren. Bericht des Inst. für angew. Strömungslehre der TU-Dresden. (Unverölfentich1).

[4] Ruchti, O. "Versuche mit Radildilfusoren" Technische Beriche 11, H. 5, S. 129 (1964).

[5] Sörgel, G. "Untersuchungen arn schaufellosen und beschaulelten Diffusor eines Radialdiffusors, Diss. TU-Dresden.

[6] Нanna, S.

"Informationen über turbulente Grenzschichten bie verschiedene Rauhigkeiten aut Grund Von Messungen an einem Radiäldilfusor". Maschinenbaurechnik, H, 6, 1978.

[7] Schlicheing, H. "Boundary Layer Theory" Mc. Craw Hill, New York 1968.

[8] Bandyopadhyay, P.R. "Rough wall iurbulent boundary Jeyers in the transition regime." 3. Fluid Wech. (1987), Vol. 180, pp. 231-266.

[9] Claser, F.H. "Turbulent boundary layers in adverse pressure gradiencs, ]. Aeronaut Sci. $20,468(153)$.

[10] Felsh, K.O. "Beitrag zur Berechnung turbulente Grenzschichten in zweidimensionaler incompressible Strömung". Diss. Karlsruhe 1963.

[II] Nipim, H. H., "Ellects caused by small discrete iwo-dimensional rouhness elements Cockrell, D.J. immersed in turbulent boundary layers." J. Fluid Mech. (1985) Vol. (.53) - pp. 17-30.

[12] Felsh, K.o. "Eine neue Methode zur Berechnung iurbulenter Grenzschichten." Wiss. Z. der TU-13resden, H. 4, 1969

[13] Harsa, S. "Unpublished work."

[14] Millor, G.L., "Cquilibrium Turbulent Boundary Layers". J. Fluid Mech. 24 (1966) Gibson, D.M.

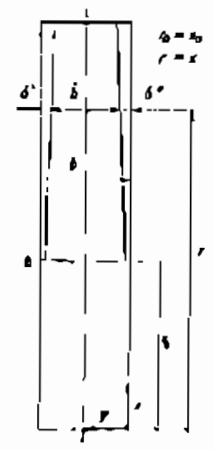

F]C. I Illuatration of coordinate gyatem on radinl diffuer 


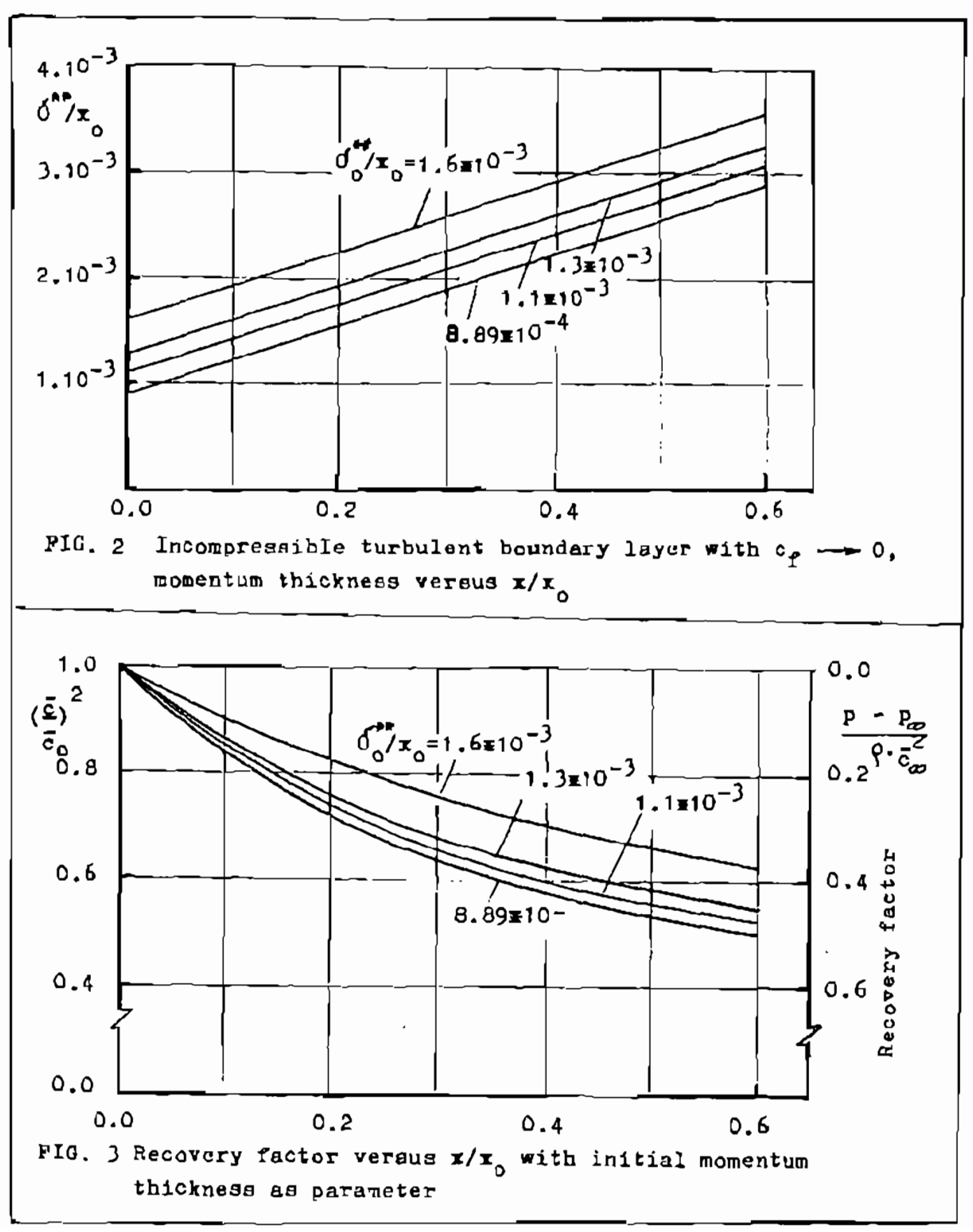




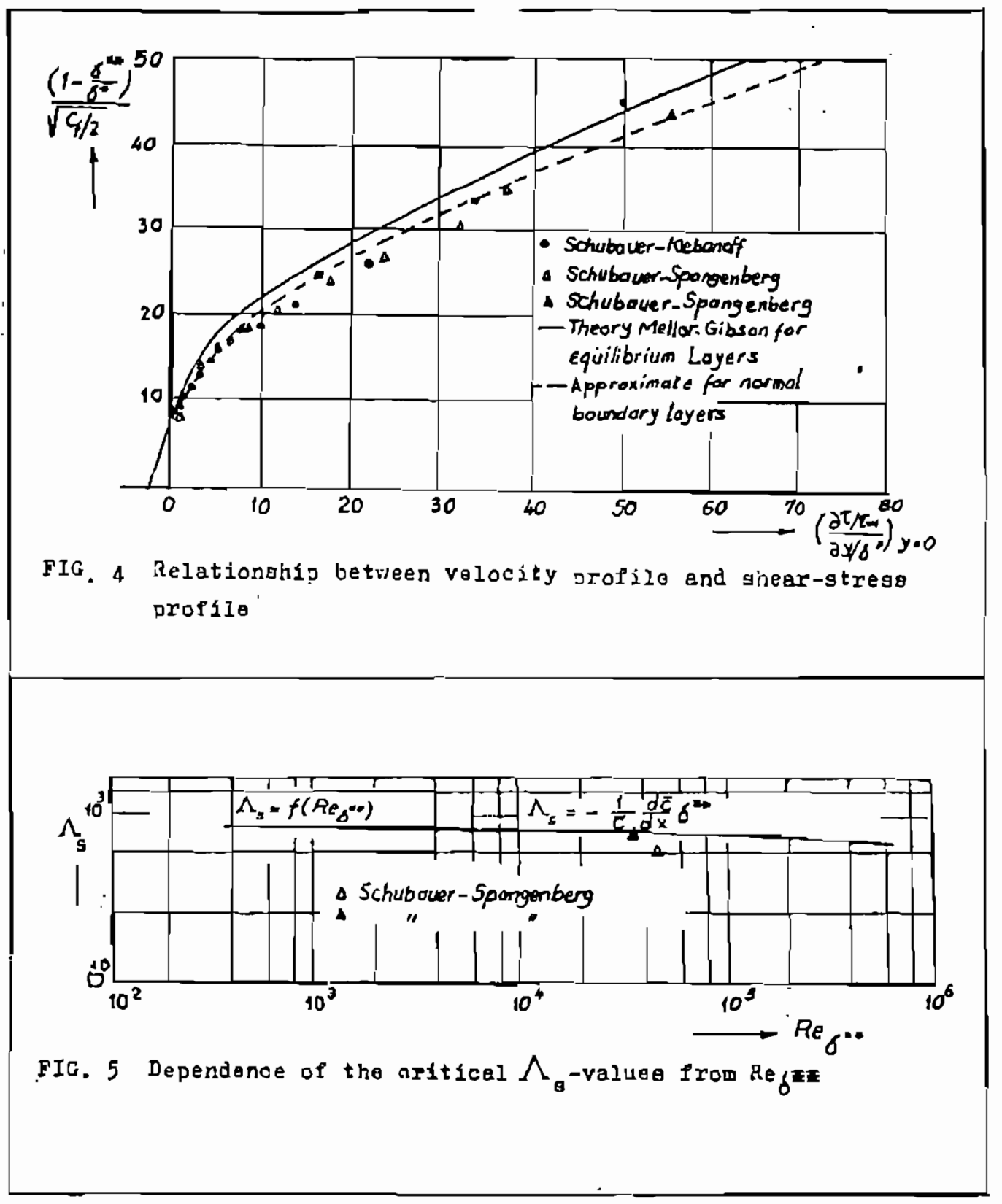

